\title{
Vapour Phase Deposition of Thin Siloxane Coatings on the Iron Surface. The Impact of the Layer Structure and Oxygen Adsorption on Corrosion Stability
}

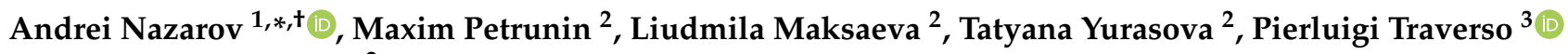 \\ and Andrey Marshakov ${ }^{2}$ \\ 1 French Corrosion Institute, 29200 Brest, France \\ 2 Frumkin's Institute of Physical Chemistry and Electrochemistry, Russian Academy of Sciences, \\ 119991 Moscow, Russia; mmvp@bk.ru (M.P.); lmaksaeva@mail.ru (L.M.); tatal111@yandex.ru (T.Y.); \\ a_marshakov@mail.ru (A.M.) \\ 3 CNR-IAS, Via De Marini 6, 16149 Genoa, Italy; pierluigi.traverso@ias.cnr.it \\ * Correspondence: nazarovandrei@neuf.fr; Tel.: +33-298-456-241 \\ + Andrei Nazarov retired form French Corrosion Institute.
}

check for

updates

Citation: Nazarov, A.; Petrunin, M.; Maksaeva, L.; Yurasova, T.; Traverso,

P.; Marshakov, A. Vapour Phase

Deposition of Thin Siloxane Coatings

on the Iron Surface. The Impact of the

Layer Structure and Oxygen

Adsorption on Corrosion Stability.

Coatings 2021, 11, 1217. https://

doi.org/10.3390/coatings11101217

Academic Editor: Rita

Bacelar Figueira

Received: 12 August 2021

Accepted: 15 September 2021

Published: 4 October 2021

Publisher's Note: MDPI stays neutral with regard to jurisdictional claims in published maps and institutional affiliations.

Copyright: (c) 2021 by the authors. Licensee MDPI, Basel, Switzerland. This article is an open access article distributed under the terms and conditions of the Creative Commons Attribution (CC BY) license (https:// creativecommons.org/licenses/by/ $4.0 /)$.

\begin{abstract}
The mechanism of iron corrosion protection by thin siloxane films was clarified. Quartz crystal microbalance technique (QCM) was applied to control the vapour phase deposition of alkoxysilanes and the formation of thin siloxane films. It was shown that the addition of water vapour increased the thickness of the grafted siloxane films. Crystal-like films spontaneously grow to 10-16 monolayers at $100 \%$ RH of Ar flow due to the catalytic effect of the surface. X-ray photoelectron (XPS) and Auger spectroscopies analysed the thin siloxane films and Scanning Kelvin Probe (SKP) showed the formation of iron-siloxane bonds passivating the iron surface. The films showed high hydrophobicity and corrosion inhibition in humid air contaminated by sulphur dioxide. Thick films were less ordered, hydrophilic and accelerated the corrosion of iron. For corrosion protection, the presence of oxygen in the atmosphere is extremely important. In a wet Ar atmosphere, contaminated by sulphur dioxide, the surfaces are not stable and quickly corroded. Oxygen adsorption stabilizes the surface oxide film that correspondingly preserves the anchoring iron-siloxane bonds and enables corrosion protection by the coating.
\end{abstract}

Keywords: self-ordering siloxane films; hydrophobicity; corrosion protection; adsorption bonds; Scanning Kelvin Probe

\section{Introduction}

Corrosion protection of metallic construction by polymeric coatings is widely applied. It was supposed that polymeric coatings protect the substrate by acting as a barrier toward water, oxygen and ions. However, oxygen and water quickly saturate the coating and these species could not be rate-determining factors of corrosion protection by advanced coatings [1,2]. Kinsella and Mayne and Mayne and Scantlebury found that ionic resistance is a key factor in polymer coating stability, known as "resistance inhibition." The relationship between the ionic resistance of a coating and its protective ability has been pointed out elsewhere [3,4] The ions in polymers diffuse relatively slowly and ionic resistance has been highlighted as an important (even critical) property of a coating in modern works [5,6]. However, additionally, the wet adhesion of the polymer to the substrate and the stability of chemical bonds at the interface can be important factors determining the overall coating lifetime [7,8]. Most polymer-metal bonds, which do not have mechanical interlocking, will ultimately fail when subjected to prolonged moisture exposure and stress [7]. The reason is that the contact of the oxidized metal surface of high surface energy and polymeric coating of low surface energy is thermodynamically unstable. At the interface, water molecules replace the polymeric coating leading to delamination. Thus, the strength of the contact of 
the epoxy polymer and $\mathrm{Al} / \mathrm{Al}_{2} \mathrm{O}_{3}$ is very weak and can be determined by water diffusion to the interface [8]. To increase the wet adhesion, the metal surface has been pre-treated, performing the interlayer of mixed organic-inorganic nature [9-12]. Hence, it is believed that the formation of the 'interphase' intermediated the nature of the inorganic substrate and the organic polymer determines the final adhesion stability of the metal-polymer joint [9].

Alkoxysilanes are often used as adhesion promoters or coupling agents, where siloxane interlayer links the metal surface and the coating [12]. To inhibit corrosion, the alkoxides of titanium or zirconium are often added to the siloxane interlayer that creates the oxides-hydroxides of these metals in the interphase. The promising properties of hybrid sol-gel-derived polymers for metals corrosion protection have attracted significant attention over recent decades [13-17]. The sol-gel process in the liquid phase consists of the creation of an oxide-hydroxide network by condensation of molecular alkoxide precursors $M(O R) n$, where $\mathrm{R}$ is typically an alkyl group $\left(\mathrm{C}_{\mathrm{x}} \mathrm{H}_{2 \mathrm{x}+1}\right)$ and $\mathrm{M}$ represents a network-forming element, such as $\mathrm{Si}, \mathrm{Ti}, \mathrm{Zr}, \mathrm{Al}, \mathrm{Fe}$, B, etc., in an alcohol or other low-molecular-weight organic solvent. Curing of these films, at elevated temperature, leads to significant improvement of corrosion protection [13]. Thus, the condensation of unreacted silanol or alkoxy groups in the film results in the formation of a Si-O-Si- network with enhanced barrier properties [15-17].

A silane precursor is a binder that creates a siloxane network and performs chemical bonds with a metal surface. For example, for aluminium surface, FTIR revealed two modes of interaction, one between silane and $\mathrm{Al}^{3+}(\mathrm{Si}-\mathrm{O}-\mathrm{Al})$, and the other indicative of a siloxane network ( $\mathrm{Si}-\mathrm{O}-\mathrm{Si})$. Thickness measurement showed that the layer is $100-200 \mathrm{~nm}$ thick. Direct pull-off adhesion measurements of silane treated samples showed a significant improvement in initial bond strength compared with degreased aluminium substrates [18].

The literature data show that the synthesis and the study of thin siloxane films is an important issue for metals corrosion protection by sol-gel coatings and the development of adhesion promoters. The objective of this work is to discuss the articles describing the formation of thin siloxane films adsorbed on the iron surface from the vapour phase published elsewhere [19-23]. QCM was the main method of investigation that weigh a small part of the monolayer of the adsorbed species that gain new knowledge on layer formation. XPS and Auger spectroscopies were applied to investigate the chemical composition and Scanning Kelvin Probe (SKP) to evaluate the electrochemical structure of the metal/siloxane interfaces. The QCM method was used to determine the interaction of the modified surfaces with vapour phase water molecules and determine the surface hydrophobicity. The mass gain and the corrosion rate of iron was also monitored by QCM in high humid argon or synthetic air atmospheres contaminated by sulphur dioxide. Thus, it was possible to determine the impacts of the siloxane layer structure, presence of adhesion bonds and oxygen adsorption on the corrosion stability of the iron/siloxane joints. Experimental data used in this work were published a few decades ago in different sources [19-23] and this paper summarizes and discusses these results.

\section{Materials and Methods}

\subsection{Vapour Phase Deposition of Thin Siloxane Layers on the Iron Surface}

Figure 1 shows the schematic of the glass pipe system that was used for vapour phase silane deposition and the study of the modified iron surface [19-21]. Silane evaporates in the glass pipe system in the flow of Ar (spectral purity, the flow $1800 \mathrm{~cm}^{3} / \mathrm{min}$ ) and adsorbs on the iron surface in the QCM cell. The mass gain on the Fe surface was studied as a function of Ar humidity. Silane partial pressure in gas flow was kept constant in all experiments. To humidify Ar, the part of the flow $\left(200 \mathrm{~cm}^{3} / \mathrm{min}\right)$ was passed through the humidifier. The gas humidity in the cell was controlled during all measurements. 


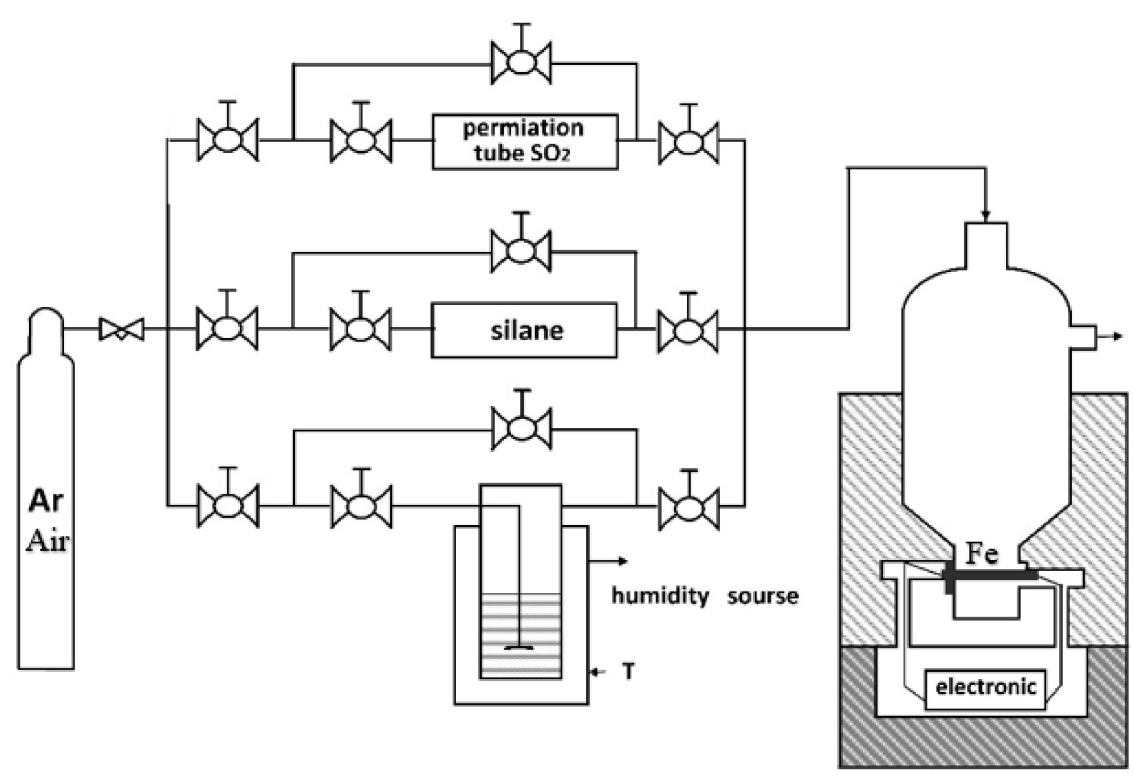

Figure 1. Schematic of the glass system and piezo quartz cell used for silane deposition, measurements of water adsorption and iron corrosion [19]. Published with permission from SPRINGER NATURE 1993.

To study the corrosion of iron covered by formed thin siloxane films, the compressed Ar was replaced with compressed artificial air (spectral purity, the mixture of $\mathrm{N}_{2} 80 \%-\mathrm{O}_{2}$ $20 \%$, flow $1800 \mathrm{~cm}^{3} / \mathrm{min}$ ) and the air was passed through a cell containing the source of $\mathrm{SO}_{2}$ (permeation tube creates the concentration of $28.6 \mathrm{mg} / \mathrm{m}^{3}$ ) [19-21]. To humidify the air (flow $200 \mathrm{~cm}^{3} / \mathrm{min}$ ), it was passed through the humidifier (Figure 1). The QCM cell was immersed in water of the thermostat that controlled the temperature at $22{ }^{\circ} \mathrm{C}$. These conditions were supported during all measurements. Adsorption of the silane, water vapours and iron corrosion were studied on the iron surface using an apparatus (Figure 1). The setup includes the cell with QCM, where the quartz with deposited iron electrode detected the mass change due to iron interaction with the vapours. Thus, adsorption of the components and the mass gain due to corrosion of the formed surfaces was determined. The minimal time of the corrosion test was $10 \mathrm{ks}$.

The vapour deposition of methyltrimethoxysilane $\mathrm{MeSi}(\mathrm{OMe})_{3}$ (MTMS), butyltrimethoxysilane $\mathrm{BuSi}(\mathrm{OMe})_{3}$ (BTMS) and $\gamma$-aminopropyltrimethoxysilane $\mathrm{NH}_{2}-\left(\mathrm{CH}_{2}\right)_{3} \mathrm{Si}(\mathrm{OMe})_{3}$ (APTMS) was investigated [19-23].

\subsection{Piezo-Quartz Microbalance}

In the study, QCM with $10 \mathrm{MHz}$ of AT-cut quartzes (20 mm diameter) were used. Two sides of the quartz disk were degreased and gold layers of $30 \mathrm{~nm}$ thick were thermosputtered in a vacuum chamber. In a second step, a near $1 \mu \mathrm{m}$ thick iron layer was thermo-sputtered on the gold layer of one side of the quartz.

The measured mass change $\Delta \mathrm{m}$ is linearly proportional to change in the frequency of the quartz as expressed Sauerbrey equation:

$$
\Delta \mathrm{m}=-\mathrm{C} \times(1 / \mathrm{n}) \times \Delta \mathrm{f}
$$

where $\mathrm{n}$ is the quartz overtone number, $\mathrm{C}$ is a constant that depends on the property of the crystal and the area of iron deposition [24]. Using measuring accuracy $0.01 \mathrm{~Hz}$ the balance sensitivity was near $10^{-9} \mathrm{~g}$. The application of QCM to the study of corrosion inhibition was reviewed in [25].

Equation (1), typically referred to as the Sauerbrey equation, constitutes the basic principle of QCM technology. This equation is only valid when the added mass is rigidly adsorbed on the quartz surface without slip. The mass is evenly distributed over the 
sensitive area (central part) of the crystal. For evaluation of adsorption, the contact (landing) area of the water molecule was assumed to be $10.5 \AA^{2}$ and a fragment of siloxane in the polymer was assumed to be $20 \AA^{2}$ [19]. Calculation using Equation (1) showed that the mass of the statistic monolayer of water decreased the QCM frequency for $6.7 \mathrm{~Hz}$, of methylsiloxane for $17.2 \mathrm{~Hz}$ and butylsiloxane for $25 \mathrm{~Hz}$ [19-21].

Thus, the calculation of the number of monolayers adsorbed by Fe surface was carried out using the decrease of QCM frequency. Taking into account that the iron had a mirror surface, the amount of adsorbed layers of molecules was determined using the geometrical visible surface of the iron. Reversible (in presence of the adsorbed molecules in the gas) and irreversible (in the pure gas atmosphere) mass gain was determined. After siloxane deposition, the corrosion rate of iron was determined using mass gain measured by QCM after desorption of water and sulphur dioxide in the dry airflow $[19,20]$.

\subsection{Scanning Kelvin Probe}

SKP (UBM Mestechnik, Dusseldorf, Germany) measures the distribution of the electron work function (ewf; $\Phi_{\mathrm{we}}$, Equation (2)) or electrochemical potential above the metal surface in the air [26]. It can be applied for bare, corroding, and polymer covered metal surfaces [27-30]. In SKP microscopy the microprobe (tip NiCr alloy diameter $70 \mu \mathrm{m}$ ) is scanning above the surface (e.g., distance $50 \mu \mathrm{m}$ ), measuring the distribution of ewf with high spatial resolution. According to the definition, ewf is the work to move an electron from the metal bulk to the point just outside the surface that does not contain non-compensated electric charges. Thus, ewf influences mainly the potential drop across metal/metal oxide $\left(\Delta \varphi_{1}\right)$ interface, the potential drop in the metal oxide $\left.\Delta \varphi_{2}\right)$ and the potential change in the dipole layer $\Delta \varphi_{3}$ ) in the polymer close to the interface (Equation (2), Figure 2):

$$
\Delta \Phi_{\text {we }} / \varepsilon=\Delta \varphi_{1}+\Delta \varphi_{2}+\Delta \varphi_{3}
$$

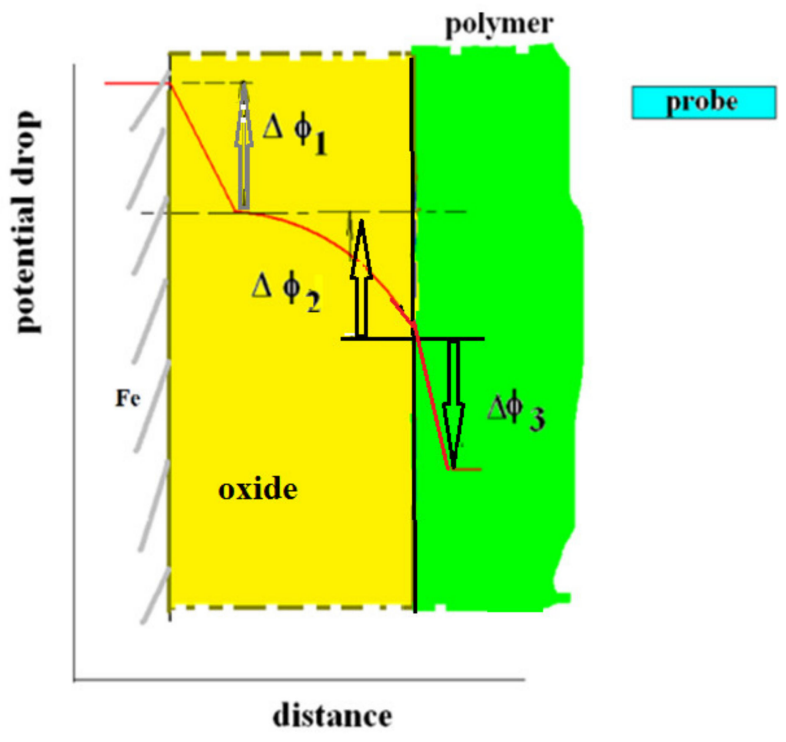

Figure 2. Schematic of potential distribution in the metal-polymer joint.

The iron is covered by a semiconducting oxide/hydroxide film. The difference in electron energies of iron and the surface oxide creates a contact potential difference (Schottky junction $\Delta \varphi_{1}$, Equation (2)) [31]. The oxide film adsorbs the species of air or functional groups of the coating that creates two potential drops. The first one is located in the oxide $\left.\Delta \varphi_{2}\right)$ and the second $\left(\Delta \varphi_{3}\right)$ in a double electric layer in the polymer. Thus, SKP provides the map of the potential drop across the metal surface, which is influenced by the nature of oxide and the polymer species. It is possible to suppose that the Helmholtz equation (Equation (3)) drawing for a parallel-plate capacitor, describes the formation of the layer of 
the ordered and oriented dipoles [32]. According to electrostatic, the potential drop in the layer of the polymer is a function of the density of the charges $(\sigma)$ and the capacitance $(C)$ of the parallel-plate capacitor.

$$
\Delta \varphi_{3}=\sigma / X=4 \pi \mathrm{N}_{\sigma} \mu / \varepsilon
$$

It is proportional to the effective dipole moment $(\mu)$ which is directed normally to the surface, $\mathrm{N}_{\mathrm{s}}$-the area occupied by the adsorbed molecule, $\varepsilon$ is the permittivity of the adsorbed molecules. The Kelvin Probe measurements in detail were carried out for Langmuir-Blodgett (LB) films on the water surface $[32,33]$.

Equation (3) describes the influence of adsorbed films on the electron work function of the oxidized metal surfaces. The sign in the potential drop is determined by the orientation of the dipoles at the interface. An increase in potential relatively non-modified substrate shows the presence of positive charges at the metal oxide surface and negative charges in adsorbate or the organic part of the polymeric coating. The positive charge on the groups of the polymer and negative on the surface of the substrate decreased the measured potential [11]. For example, SKP was applied to measure the charge separation in organic monolayers mobilized on the gold surface. The estimation of the potential drop for a monolayer of octadecanoic acid is about $700 \mathrm{mV}$ [33]. Adsorption of amines on the metals decreased the potential drop by $200-300 \mathrm{mV}$ [11]. Normally SKP tip is calibrating above reversible electrode (e.g., $\mathrm{Cu} / \mathrm{CuSO}_{4}$ ) and the electrochemical potential difference due to the formation of the layer of ordered ionic dipoles (Equation (3)) can be determined [11,33]. Thus, it is possible to compare the potential for differently treated surfaces. For application to protective coatings, the SKP technique was described in the review in more detail [30].

\section{Experimental Results}

\subsection{QCM Application for Monitoring of Siloxane Films Adsorption on the Iron Surface}

Monitoring of the frequency of Fe electrodes in the QCM cell after letting the vapours of butyltrimethoxysilane (BTMS) in the flow of Ar is shown in the figure. Before measurements, the surface of iron was cleaned for 3-4 $\mathrm{h}$ in the flow of pure Ar until the frequency stabilization was reached (Figure 3).

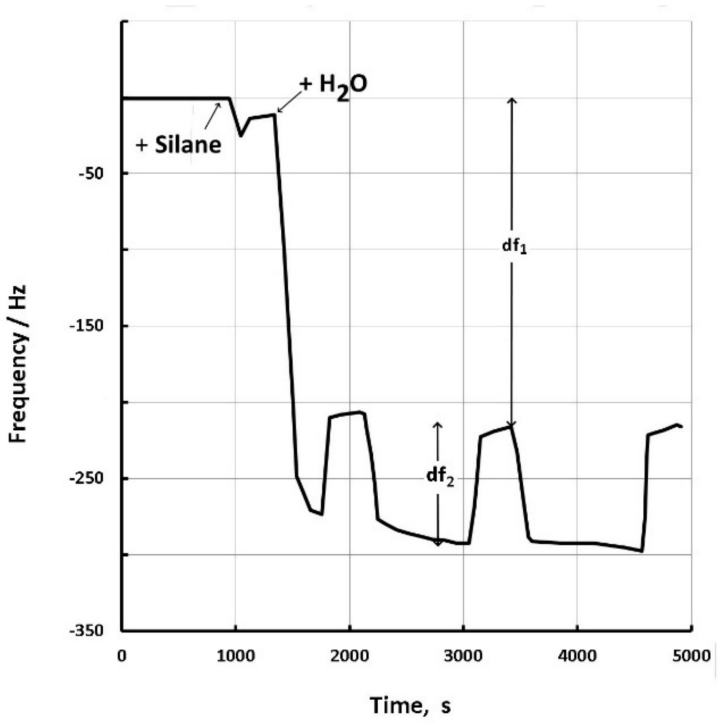

(a)

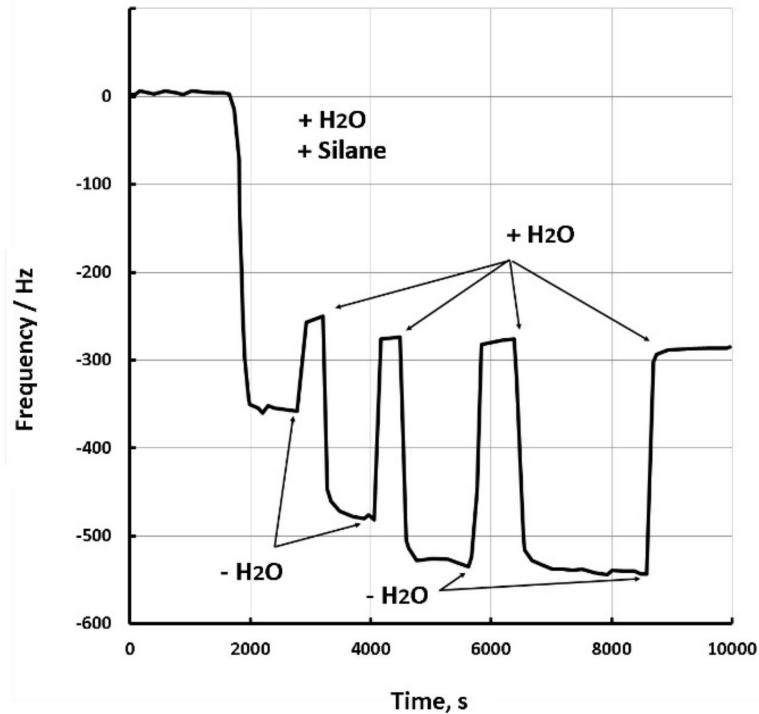

(b)

Figure 3. Monitoring of the frequency of iron QCM upon insertion of water and BTMS vapours. (a) — the humidity of Ar flow is 71\% RH and (b)—98\% RH [19]. Published with permission from SPRINGER NATURE 1993. 
Initially, a vapour of pure BTMS was added to Ar flow ( $0 \% \mathrm{RH})$ that decrease the frequency by $20 \mathrm{~Hz}$ (Figure 3a). Taking into account that the landing area of a molecule of siloxane is $20 \AA$ the coverage by irreversibly adsorbed siloxane is about one monolayer. Co-adsorption of BTMS and water vapours significantly decreased the frequency due to bigger mass gain (Figure 3). Passing the flow of pure Ar increased the frequency due to the desorption of non-reacted species. The measurements were performed at the fixed concentration of BTMS and the humidity $71 \%$ and $98 \% \mathrm{RH}$. Increased gas humidity increased variation of the frequency in water adsorption-desorption transients ( $\mathrm{df}_{2}$, Figure $\left.3 \mathrm{a}\right)$. After a few adsorption-desorption transients the frequency in dry conditions stabilized at 220 and $280 \mathrm{~Hz}$, correspondingly. The decrease of the frequency $\left(\mathrm{df}_{1}\right.$, Figure $\left.3 \mathrm{a}\right)$ relates to the mass gain of irreversibly adsorbed molecules of BTMS.

Using Furie Transform Infrared Spectroscopy (FTIR) spectroscopy (Nickolet, Dusseldorf, Germany) and Auger spectroscopy (JEOL JAMP-9500F FE, MA, USA) was shown the formation of thin siloxane films $[19,20]$. Figure 4a compares the QCM frequency decrease related to the mass gain of BTMS films, which were deposited in argon of different humidities. It can be pointed out that increase of humidity from $0 \%$ to $100 \% \mathrm{RH}$ increases the thickness of irreversibly adsorbed butylsyloxane from 1 to 12 monolayers. However, further siloxane growth vanished (Figure 4a). The water adsorption by the coating also reached steady-state conditions. Thus, the catalytic effect of the oxidized iron surface and the growth of the film was limited to 12 monolayers. It can be supposed that the substrate assembles the silane and water molecules, accelerating the condensation and the formation of the $\mathrm{Fe}-\mathrm{O}-\mathrm{Si}$ and $\mathrm{Si}-\mathrm{O}-\mathrm{Si}$ bonds.

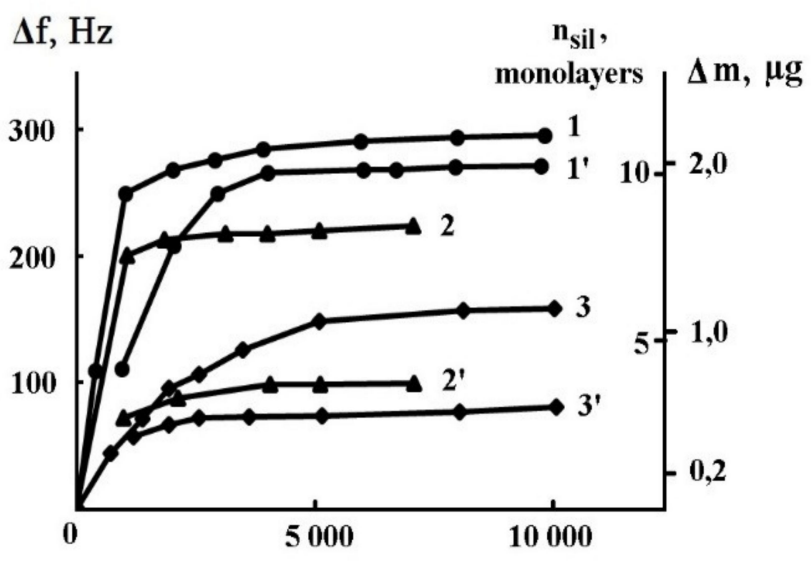

(a)

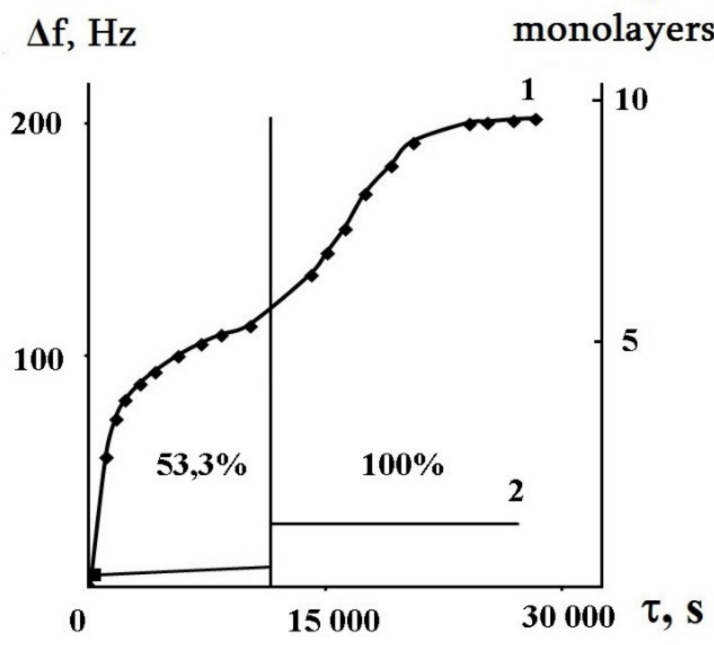

(b)

Figure 4. (a)-Variations of the QCM frequency and mass gain due to irreversible adsorption of BTMS $(1,2,3)$ as a function of the humidity (1-100\% RH; 2-71\% RH and 3-53.3\% RH). 1', $2^{\prime}$ and $3^{\prime}$ are the changes of frequency and the mass of reversibly adsorbed water. (b) - monitoring of the frequency and the thickness of MTMS film as a function of Ar humidity [20]. Published with permission from NAUKA/INTERPERIODIKA 1994.

A similar experimental setup was applied to study the adsorption of methyltrimethoxysilane (MTMS). The experiment in Figure $4 \mathrm{~b}$ shows that at the same concentration of MTMS vapour in the flow, the increasing of Ar humidity from $53.3 \%$ to $100 \%$ RH additionally decreased QCM frequency related to deposition of about nine statistic monolayers of the siloxane.

Figure 5 compares the variation of QCM frequency and the mass gain during adsorption of MTMS and BTMS in argon of relative humidity 53.3\% and 100\% RH. Water adsorption on the silane-modified surface increased from one to two statistic monolayers. No water condensation was observed at 100\% RH on the siloxane coated iron (Figure 5a). 
On the other hand, for the bare iron surface, at the humidity $100 \% \mathrm{RH}$, the frequency of QCM continuously decreased due to vapour condensation and creating of thick water film [20]. Figure 5b compares the thicknesses of MTMS and BTMS irreversibly adsorbed films (in monolayers) as a function of Ar humidity. The thickness proportionally increased with the rise of humidity and BTMS forms thicker films relatively MTMS [19]. However, in all cases, the thickness of spontaneously adsorbed siloxane was limited by $5-12$ monolayers. Similar results were obtained in different works $[19,20]$.

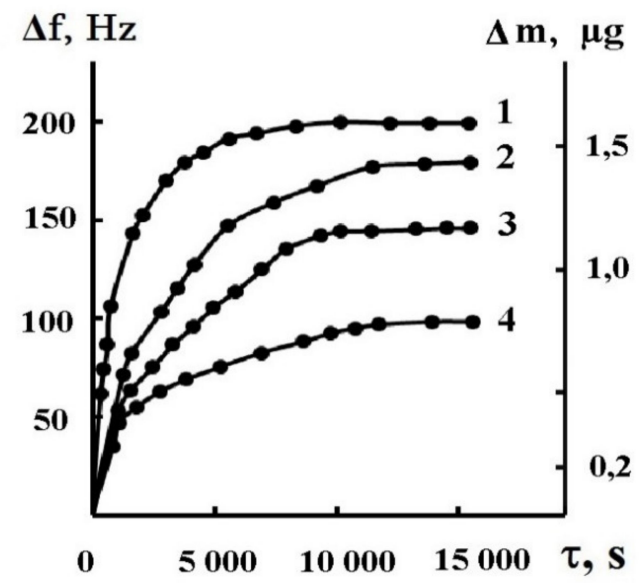

(a)

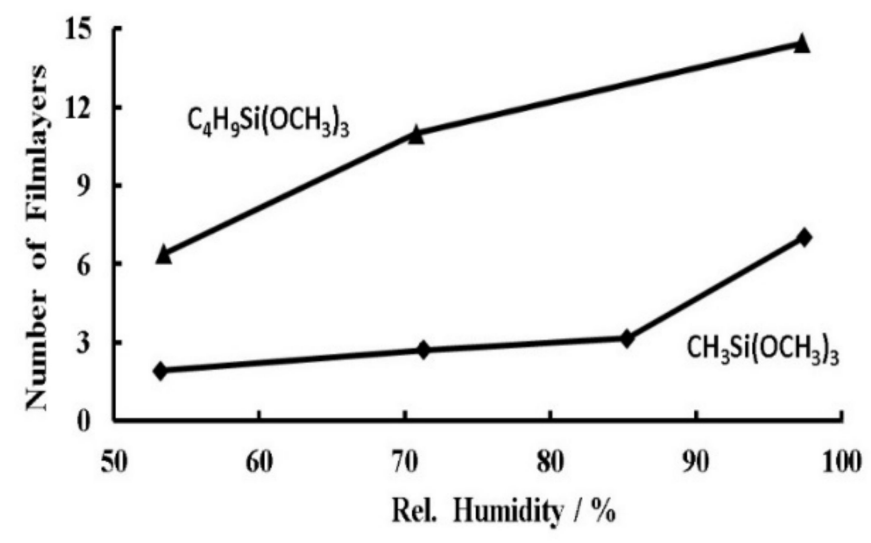

(b)

Figure 5. (a) - Variation of the frequency of iron QCM and calculated mass gain as a function of irreversible adsorption of MTMS $(2,4)$ and BTMS $(1,3)$. The Ar humidity was $53.3 \% \mathrm{RH}(3,4)$ and $100 \% \mathrm{RH}(1,2)$ [20]. (b)-the films thicknesses (monolayers) vs. relative humidity of Ar used at the deposition [19,20]. Published with permission from NAUKA/INTERPERIODIKA 1994.

\subsection{Surface Analyses of Thin Siloxane Films by Auger and XPS Spectroscopies}

After QCM experiments, some of the surfaces were investigated using Auger and XPS spectroscopy (VERSAPROBE, Goteborg, Sweden) [20,21]. An increase of the BTMS film thickness from 5 to 12 monolayers decreased the intensity of the lines from Fe substrate (Figure 6a). XPS data (Si 2p) show that the silane is mainly adsorbing as thin siloxane film (Figure $6 \mathrm{~b}$ ), because in AES, the collection depth of electrons is limited by $5 \mathrm{~nm}$ the method permits analysis of the first 2-5 atomic layers [34]. Thus, these measurements show the deposition of very thin siloxane layers during exposure of Fe in water-silane vapours.

In [19] FTIR was applied to study vapour phase BTMS adsorption on the iron surface in the flow of Ar of different humidity. The spectra detected the weak absorbance at $1050 \mathrm{~cm}^{-1}$ corresponding to $v_{\mathrm{a}}$ band of Si-O-Si fragment in 10 monolayers of BTMS film [19]. Thus, the siloxane close to the interface can be described by the schematic displayed in Figure 6d. The Brönsted acid-base interactions (Equations (4) and (5)) at the interface performs the layer of the oriented ionic dipoles related to iron siloxane bonds. The application of SKP for the detection of the charge separation at the interface will be discussed in the next chapter.

The data concerning Fe surface are in agreement with FTIR spectroscopy study of the siloxane film grafted to $\mathrm{Al}$ surface from methanol [18]. The thickness of the films was in the range 100-200 $\mathrm{nm}$ which is in the range 5-10 monolayers. However, $\gamma$ glycidoxypropyltrimethylsilnane adsorbed from methanol creates the near monolayer film [35]. Secondary ion mass-spectroscopy of the surface showed the existence of primary $\mathrm{Fe}-\mathrm{O}-\mathrm{Si}$ bonds and the thickness of the siloxane layer near $1.7 \mathrm{~nm}$. The self-limiting gas phase adsorption of the organofunctional alkoxysilane molecules leads to large area thin films close to monolayer coverage on the surfaces of silicon wafers [36]. In the nanoscale 
region, the ultra-thin siloxane films revealed smooth and uniform surfaces without any agglomeration or nucleation effects [36]. It is in line with the results of the particular study.

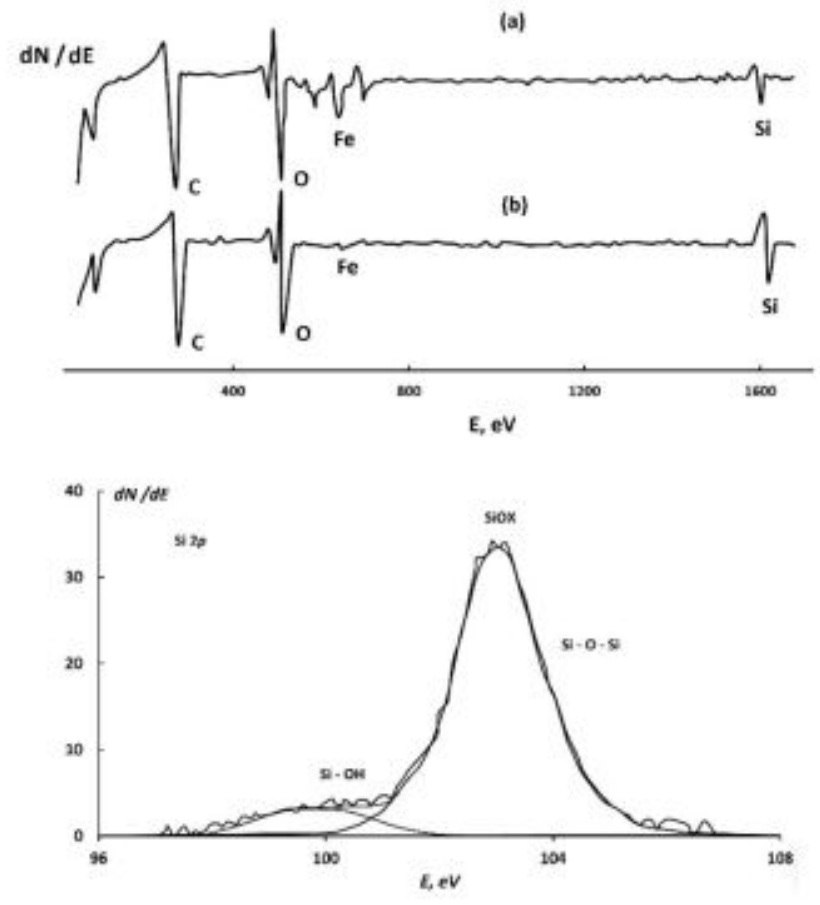

(c)

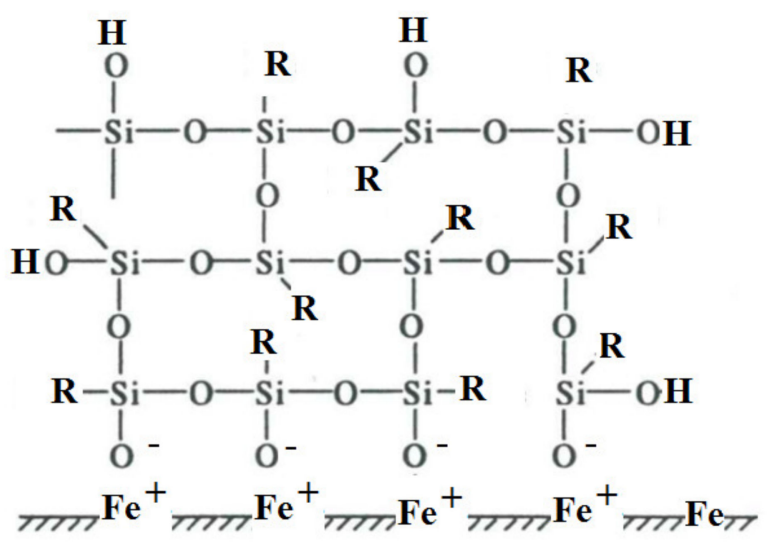

(d)

Figure 6. Auger $(\mathbf{a}, \mathbf{b})$ and XPS spectra (c) of thin films after BTMS vapour deposition on the iron surface. (a) - 5 monolayers, $(\mathbf{b}, \mathbf{c})$-12 monolayers. (d)—schematic drawing of the oxidised iron surface with adsorbed siloxane [21]. Published with permission from NAUKA/INTERPERIODIKA 1994.

\subsection{Application of SKP to Study of Metal-Siloxane Interface}

The mechanism of the bonding of polymeric films to a metal surface is an important issue. The nature and stability of the bonds to hydrolyse controls the coating delamination and correspondingly the substrate corrosion [30]. The charge separation across the metalpolymer interface can be determined by SKP. For instance, the interaction of different epoxy resins with Zn surface was studied by SKP in $[11,30]$. It was shown that different amino hardeners interact with $\mathrm{Zn}$ surface differently that controls the formation of the metal-polymer interphases [11]. The chelate forming diamines were most effective to improve the coating adhesion in water and the stability of epoxy resin to delamination. The diamines strongly interact with a surface oxide film and significantly decreased the potential of the interface. Similar results were pointed out in [37].

The adsorption of functional groups of the polymer on the surface of iron oxide can take place using Lewis and Brönsted acid-base sites on $\mathrm{Fe}_{\mathrm{x}} \mathrm{O}_{\mathrm{y}} \mathrm{OH}_{\mathrm{z}}$ surface. The significant charge separation and formation of interfacial dipoles can be a result of the Brönsted acid-base interactions (Equations (4) and (5)).

$$
\begin{gathered}
\mathrm{OFe}-\mathrm{OH}+\mathrm{HN}-\mathrm{RR}^{\mathrm{a}} \rightarrow \mathrm{OFeO}^{-+} \mathrm{H}_{2} \mathrm{~N}-\mathrm{RR} \\
\mathrm{OFe}-\mathrm{OH}+\mathrm{H}-\mathrm{OSi}(\mathrm{O})_{2} \mathrm{R} \rightarrow \mathrm{OFe}^{+-} \mathrm{OSi}(\mathrm{O})_{2} \mathrm{R}+\mathrm{H}_{2} \mathrm{O}
\end{gathered}
$$

Adsorption of the amines creates the dipoles with a positive charge on the amino groups and the negative one on the iron oxide surface of the substrate (Equation (4), Figure 7). Normally, the formation of this kind of dipoles decreases the ewf and the potential measured by SKP for the different metals [38-41]. For example, the effect of the vapour deposition of 1.6 hexanediamine on the left part of the iron surface is shown in 
Figure 7a [40]. At the left-hand side of the profile, the potential decreased for $300 \mathrm{mV}$ relatively bare iron surface (right-hand side) due to the formation of dipoles (Figure $7 \mathrm{~b}$ ).

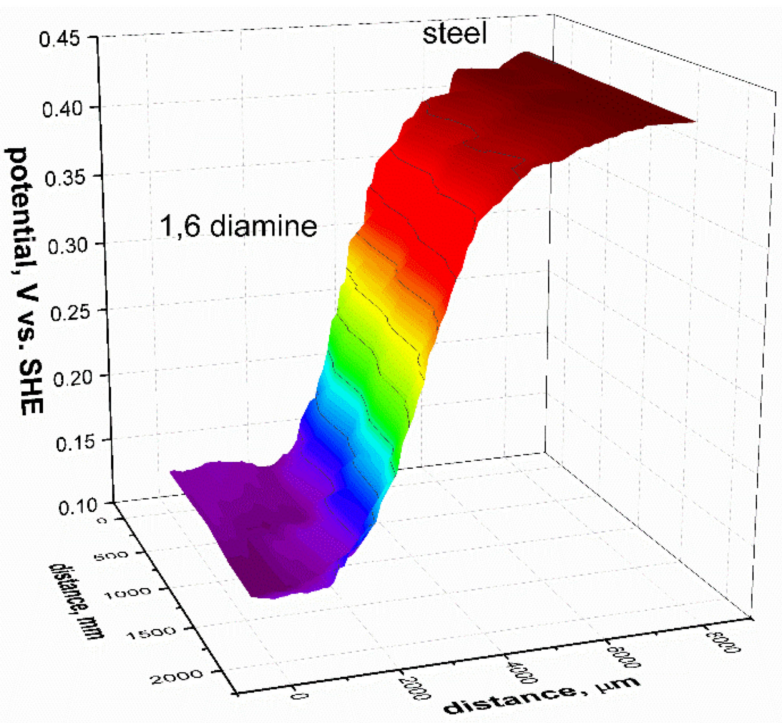

(a)

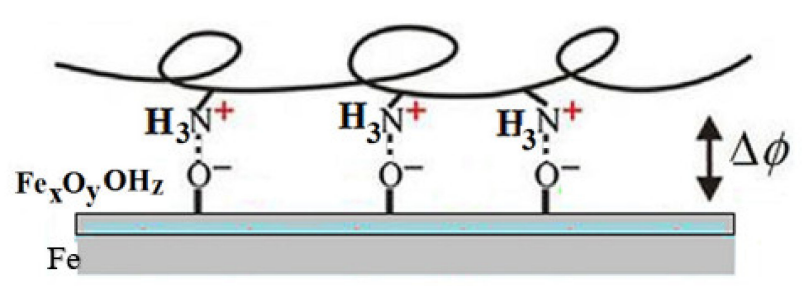

(b)

Figure 7. (a)—Potential distribution across iron surface partially covered by 1.6 diaminohexane (left-hand side), (b)—the schematic of charge distribution for Fe surface contacting with amino-containing polymer [11,41].

SKP was applied to describe the interaction of the silane coupling agent with the iron surface [22]. Figure 8 shows potential distribution above the surface with locally deposited BTMS and $\gamma$-aminopropyl trimethoxysilane (ATMS) [22,39]. Thick siloxane islands $(4 \mu \mathrm{m}$ thick) were deposited using a droplet of water solutions of the silanes [22]. After drying in ambient air, the potential distribution was measured (Figure 8). It was found that butylsiloxane increased the potential of the Fe for $300-500 \mathrm{mV}$ and the aminosiloxane decreased the potential for $300-350 \mathrm{mV}$. The different signs of the potential drops across siloxane-iron joints can show the different structures of the interface.

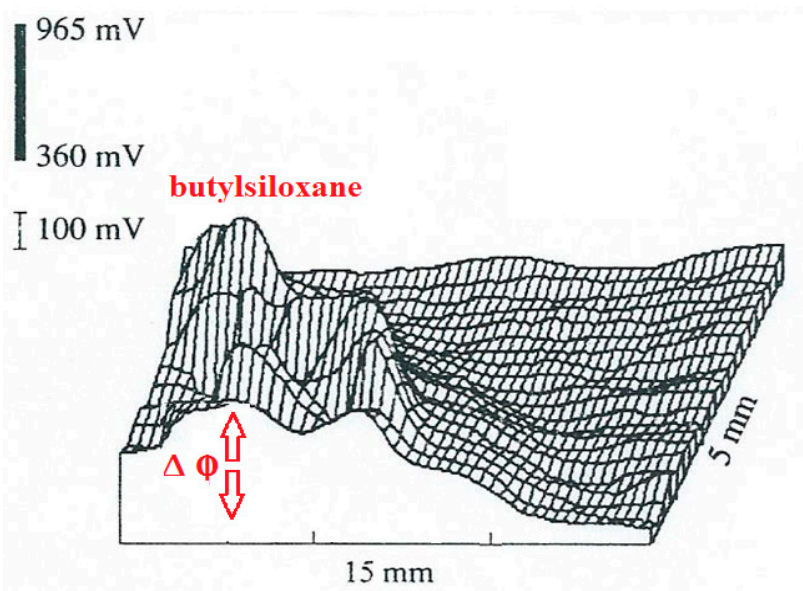

(a)

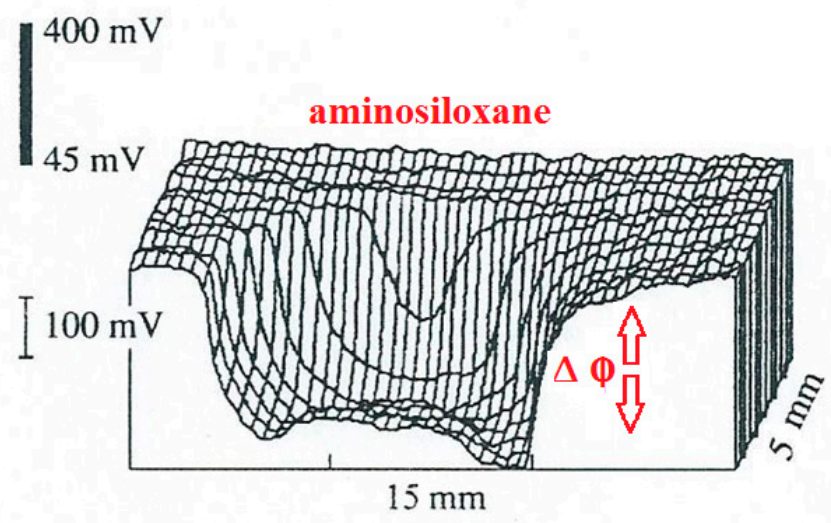

(b)

Figure 8. Potential distribution above iron surface with local deposits of BTMS (a) and ATMS (b) siloxanes [22]. SKP measurements were performed in ambient air at $60 \% \mathrm{RH}$ and the potential is given vs. standard hydrogen electrode (SHE). Published with permission from Pleiades Publishing, Ltd.

It was supposed [22] that butylsiloxane created Fe-O-Si bonds performing the dipoles with minus on oxygen of siloxane and positive charge on iron oxide (Figure 5, Equation (5)). APTMS additionally to Fe-O-Si bonds (Figure 5) can interact with oxide using the amino- 
group (Figure $7 \mathrm{~b}$, Equation (4)). The potential decreased for $350 \mathrm{mV}$ which shows the significant surface coverage by amino groups. In more detail, the application of SKP for the description of the metal-polymer bonds was discussed in [30].

The main goal was to use SKP to analyse thin siloxane layers adsorbed on the iron surface from the vapour phase. The part of the surface was masked to protect the surface from the adsorption that creates a reference surface. Fe sample was inserted into the container with BTMS and water vapour sources [22]. Figure 9 shows SKP potential distribution across the iron surface with pre-adsorbed BTMS (right-hand side). The adsorbed siloxane increased the iron potential for $200-250 \mathrm{mV}$ and $300-350 \mathrm{mV}$. The positive potential drop shows the formation of iron-siloxane interfacial dipoles (Figure 6d).

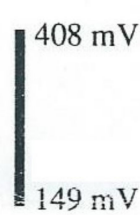

(a)
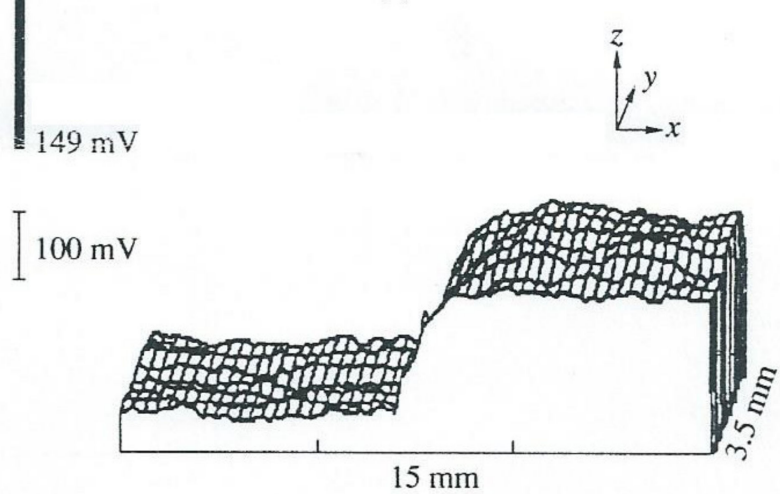

(b)
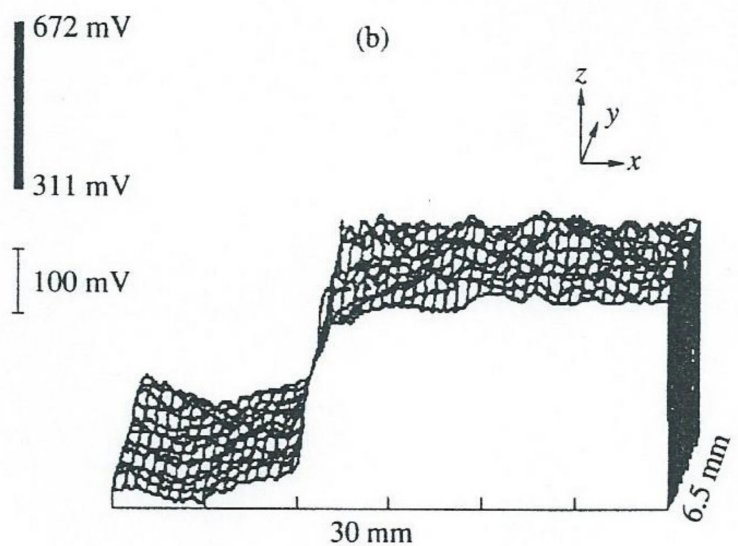

Figure 9. The potential distribution above the iron surface with vapour phase adsorbed BTMS (right-hand side). (a)— adsorption in the air at 20\% RH and (b) -adsorption in the air at 100\% RH. SKP measurements were performed in ambient air at $60 \%$ RH and the potential is given vs. SHE [22]. Published with permission from Pleiades Publishing, Ltd.

APTMS coupling agent can be adsorbed by amino-group $\left(\mathrm{Fe}-\mathrm{O}^{-+} \mathrm{NH}_{3} \mathrm{R}\right)$ or perform oxane-type (Fe-O-Si) bonds to the metal surface $[12,37]$. Thus, the orientation of the charges at the interface and the formation of polar bonds can be determined by SKP [11,22]. In contrast to BTMS, vapour deposited thin film of aminosiloxane decreases the potential for $-20--50 \mathrm{mV}$ which can be a result of initial silane adsorption by amino-groups (Figure 10a). However, exposure in Ar at 100\% RH changes the negative sign to positive relative to bare iron surface and the value of the potential drop was near $+150 \mathrm{mV}$ (Figure 10b). It can be supposed that initially, the coordination takes place using amino groups and further takes place the reorientation of the molecules with the formation of more stable iron-siloxane bonds. Adsorption of the APTMS in Ar at relative humidity $100 \%$ RH directly creates iron-siloxane bonds with a positive potential drop near $+230 \mathrm{mV}$ (Figure 10c).

The effect of ion-exchange interactions and the presence of different ionogenic groups in the grafted siloxanes on the corrosion stability of the metals was discussed in [17]. The positive charge in amino siloxane increased the concentration of $\mathrm{Cl}^{-}$a nearby surface that activates the pitting corrosion and the negative charge in the grafted siloxane inhibits the corrosion. This property of siloxanes was important for corrosion protection of $\mathrm{Al}$ using surface pre-treatments before epoxy coating application. Thus, ionogenic groups in siloxane influenced the migration of $\mathrm{Cl}^{-}$ions and the development of filiform corrosion underneath epoxy coating [42]. 


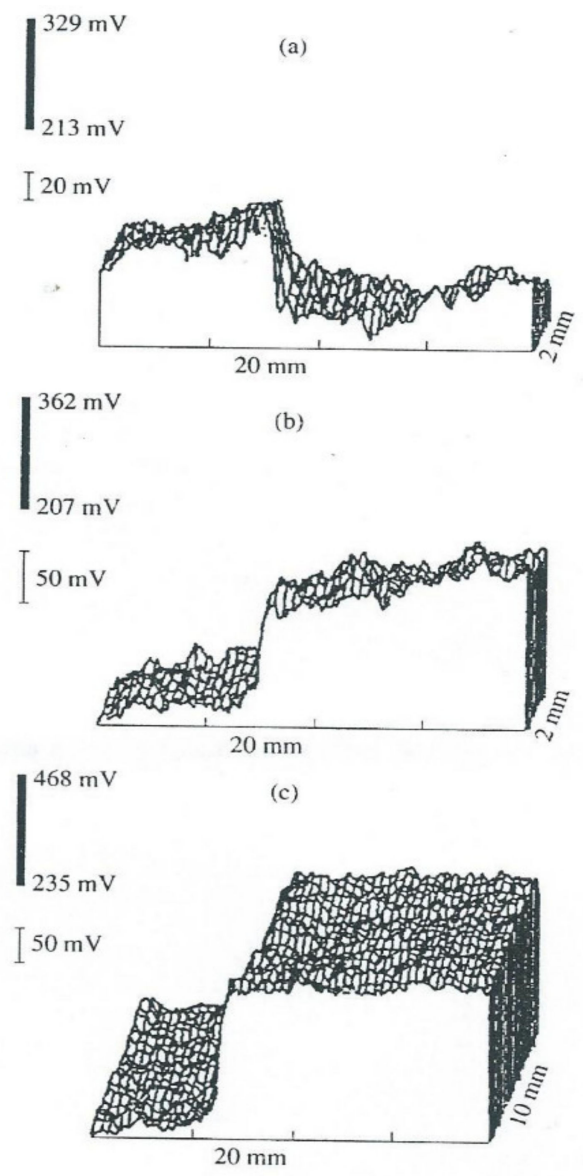

Figure 10. SKP mapping of Fe surface with vapour deposited APTMS (right hand side). (a)adsorption in Ar at RH 20\%, (b)—the same surface after exposure in Ar 100\% RH, (c) - the surface with adsorbed APTMS in Ar 100\% RH. SKP measurements were performed in ambient air at $60 \%$ RH and the potential is given vs. SHE [22]. Published with permission from Pleiades Publishing, Ltd.

\subsection{Water Adsorption and Corrosion of Siloxane Modified Iron Surface}

For atmospheric corrosion protection, hydrophobic polymeric coatings must be applied. Thus, hydrophobic-hydrophilic properties of the modified surfaces were determined using QCM in Ar flow of different humidity (Figure 11a).

An increase in humidity increased the adsorption of water. At $100 \% \mathrm{RH}$, the bare iron surface decreased the frequency by more than $3 \mathrm{kHz}$ showing the water condensation. Thin siloxane films create hydrophobic surfaces and water condensation did not observe. Probably, thin films of MTMS and BTMS are structured (Figure 6d) and show the lowest ability to water adsorption. Data in Figure $11 \mathrm{~b}$ monitors the stability of the modified surfaces during exposure to water vapour at $100 \% \mathrm{RH}$. With time, the reversible and irreversible mass gain increased showing grow of water adsorption. MTMS film was less affected than BTMS film. It can be related to the crystal-like structure of this film. In general, all thin siloxane films (10-12 monolayers) were hydrophobic. These films are spontaneously adsorbed on an iron surface and the thickness was determined by Ar humidity. However, using long time exposure of thin films at $100 \%$ RH (Figure 11b) and exposure in silane-water vapours the additional deposition of siloxane was carried out [20]. Thick films (18-35 monolayers calculated for uniform deposition) adsorbed more water relative to the bare iron surface and were less hydrophobic which can be related to non-uniform adsorption of siloxane with disordered structure (Figure 11c). 


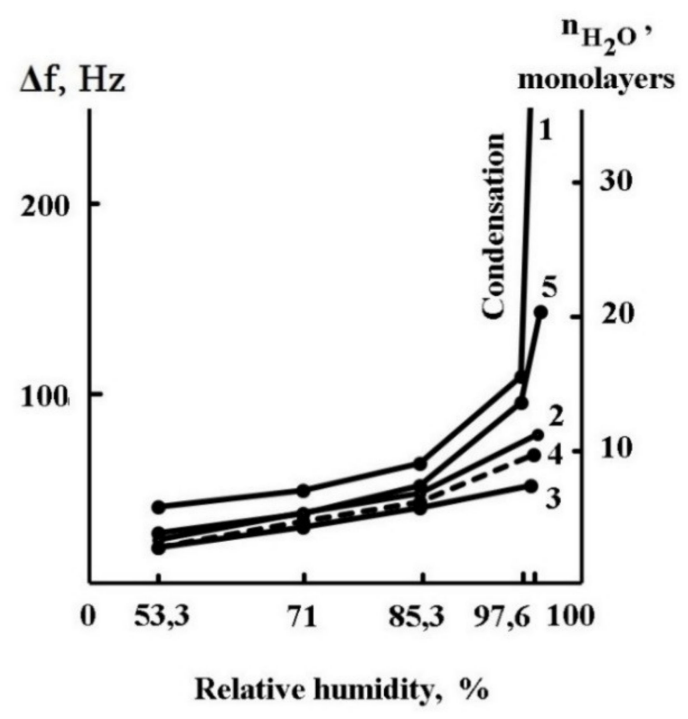

(a)

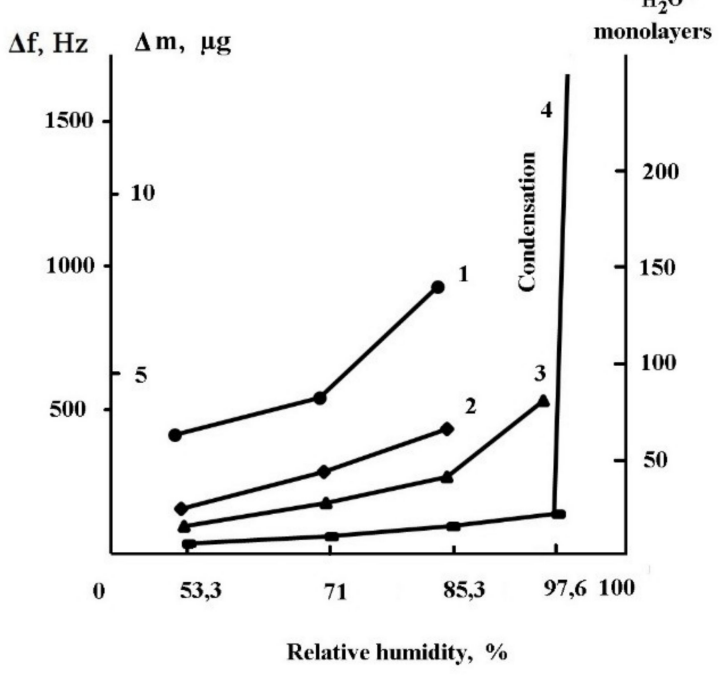

(c)

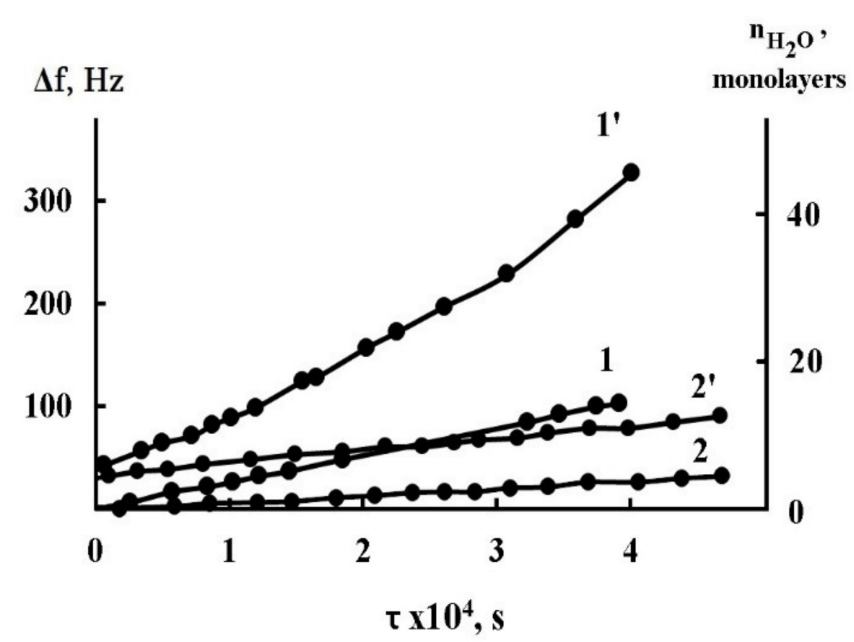

(b)

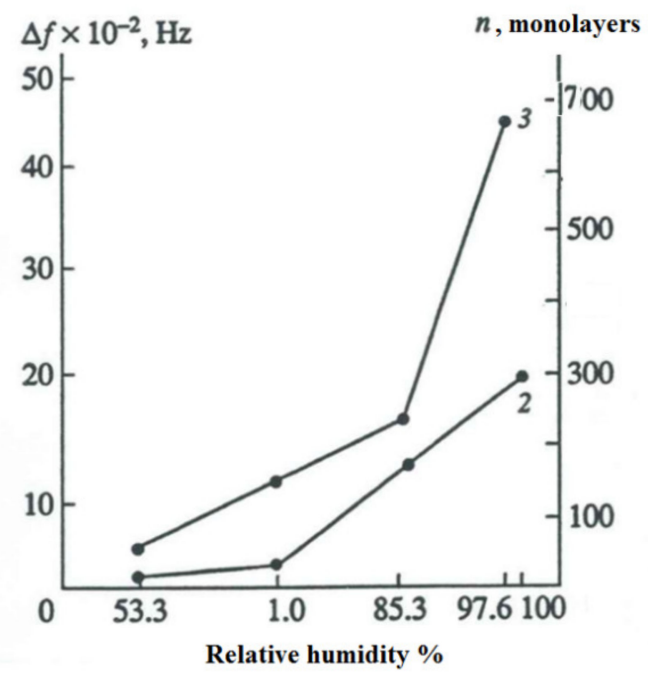

(d)

Figure 11. (a)-QCM detection of water adsorption on the iron surface with pre-adsorbed siloxanes as function of Ar humidity (a). 1-bare Fe surface, 2-MTMS 5 monolayers, 3-MTMS 10 monolayers, 4-BTMS 6 monolayers, 5BTMS 12 monolayers. (b)-Monitoring of the frequency change and water layers gain during long time exposure of the modified surfaces in Ar flow at 100\% RH. 1, 1'-BTMS and 2, 2'-MTMS. 1, 2-measurements in Ar 0\% RH and 1', 2' measurements in Ar at $100 \%$ RH. (c)—water adsorption vs. Ar humidity on thick siloxane films. 1-MTMS 35 monolayers, 2-BTMS 28 monolayers, 3-BTMS 18 monolayers, 4-bare iron surface. (d) -frequency decrease and calculated gain of water adsorption on thin films 2, 3 (Figure 11a) after addition $\mathrm{SO}_{2}$ in Ar atmosphere. Published with permission from NAUKA/INTERPERIODIKA 1994.

QCM technique was employed to determine the corrosion rate of iron. Ar was replaced with artificial air of different humidity and $\mathrm{SO}_{2}$ gas was introduced into the airflow. The decrease of the frequency was interpreted as mass gain due to water adsorption and iron corrosion (Equation (1)). FTIR and QCM detected that the time delay of iron corrosion in the air at $98 \%$ RH is $9600 \mathrm{~s}$ with grafted 10 monolayers BTMS film and for the bare iron surface is $180 \mathrm{~s}$ [19]. To determine corrosion rate contaminated air was replaced by pure air and mass gain was determined after frequency stabilization [21]. The minimal time of exposure was $10 \mathrm{ks}$ in $\mathrm{SO}_{2}$ contaminated air (Figure 12). 


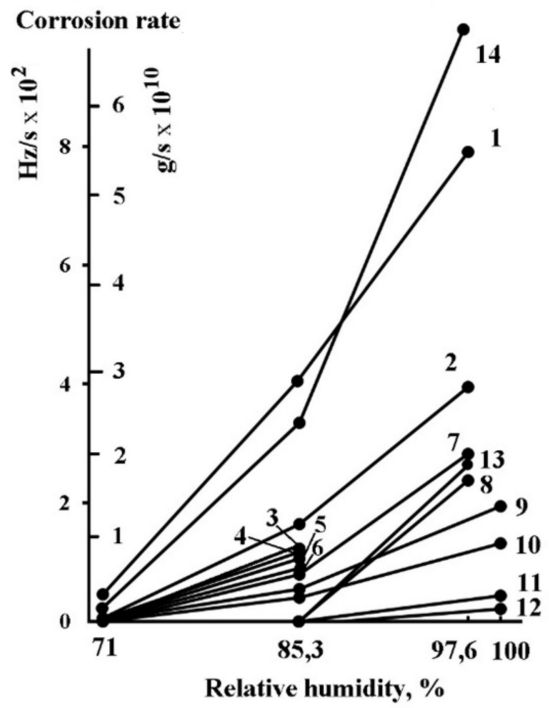

(a)

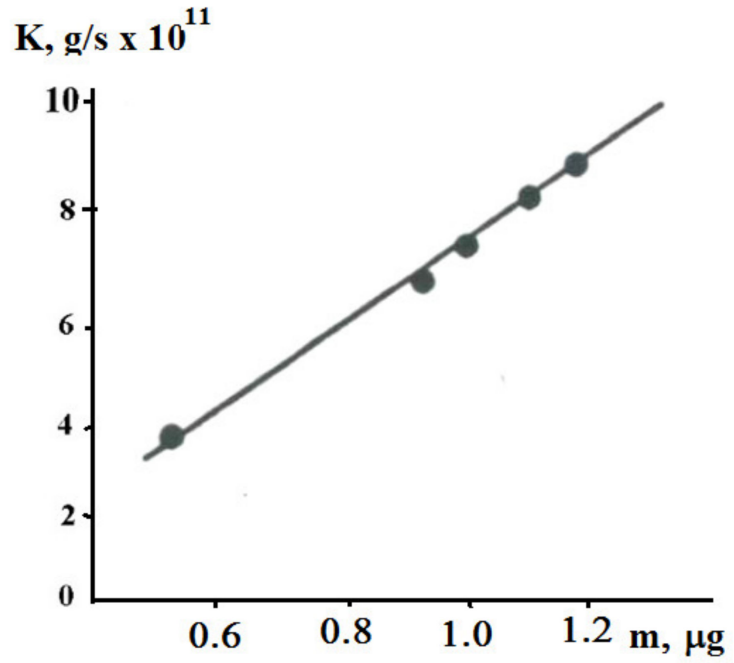

(b)

Figure 12. (a)-QCM measurements of iron corrosion rate in the air of different humidity with grafted thin siloxane films; 1-bare iron, 2-6, 9, 10 thin BTMS films of 6-12 monolayers; 7, 8, 13-one monolayer MTMS films; 11, 12-MTMS films 3 and 6 monolayers, 14-BTMS 18 monolayers. (b)—Fe corrosion rate vs. water adsorption in the air at 85.3\% RH [21]. Published with permission from NAUKA/INTERPERIODIKA 1994.

Figure 12a (curves 11,12) show strong corrosion inhibition by thin MTMS films. These films are hydrophobic and can inhibit corrosion at $100 \%$ RH (Figure 12a). Increase the thickness and disordering of the film can increase the water adsorption (Figure 11c) and accelerate corrosion (Figure 12a, curve 14). The direct dependence of corrosion rate for different films from the amount of adsorbed water was found in the air at $85.3 \% \mathrm{RH}$ (Figure 12b). Thus, the structure and hydrophobicity of siloxane are extremely important for corrosion protection by thin films. Monolayer films (Figure 12a, curves 7, 8, 13) show inhibition in relatively mild conditions at $85.3 \% \mathrm{RH}$ but they fail for protection at $100 \%$ RH air.

Figure 13 shows Scanning Electron Microscopy (VERSAPROBE, Goteborg, Sweden) images of the salinized iron surface with different BTMS layer thickness after corrosion test $10 \mathrm{ks}$ in the air at $100 \% \mathrm{RH}$. Thin spontaneously formed crystal-like BTMS shows filiform corrosion. The dimensions of the corrosion events are in the range of the dimensions of the grains. It can be supposed that corrosion of iron starts at the grains boundaries where the BTMS film is less ordered and can be less protective. In opposite, the image of the surface of siloxane with 18 monolayer film (it was calculated for uniform deposition of siloxane) on the QCM electrode shows island-like corrosion morphology (Figure 13b). This film shows low inhibition of corrosion (Figure 12a, curve 14) that has a localized character. It can be supposed that the film has hydrophilic islands adsorbing water and accelerated corrosion of iron.

The results show that thin siloxane films are sufficiently hydrophobic and are effective for protection in an aggressive atmosphere. However, in wet argon atmosphere that contained the same amount of $\mathrm{SO}_{2}$ the films are non-protective (Figure 11d). At $97 \%-100 \%$ RH the films quickly lose the hydrophobicity and adsorb 300-700 monolayers of water. The corrosion spots were observed after $10 \mathrm{ks}$ of exposure [21]. It is completely different from stability in the air atmosphere (Figure 12a) [20]. Thus, the oxygen in the air inhibits the adsorption of water and iron corrosion for particular systems. The passiveating impact of oxygen is well known to preserve the stability of the iron oxide film, the film composition and the structure. The siloxane films are anchored to the oxide film. In Ar atmosphere, the oxide film is reducing that breaks the $\mathrm{Fe}-\mathrm{O}-\mathrm{Si}$ bonds that permit the water adsorption 
and vanished the corrosion inhibition. This experiment shows the important passivating influence of oxygen for the stabilization of the metal-polymer interface.

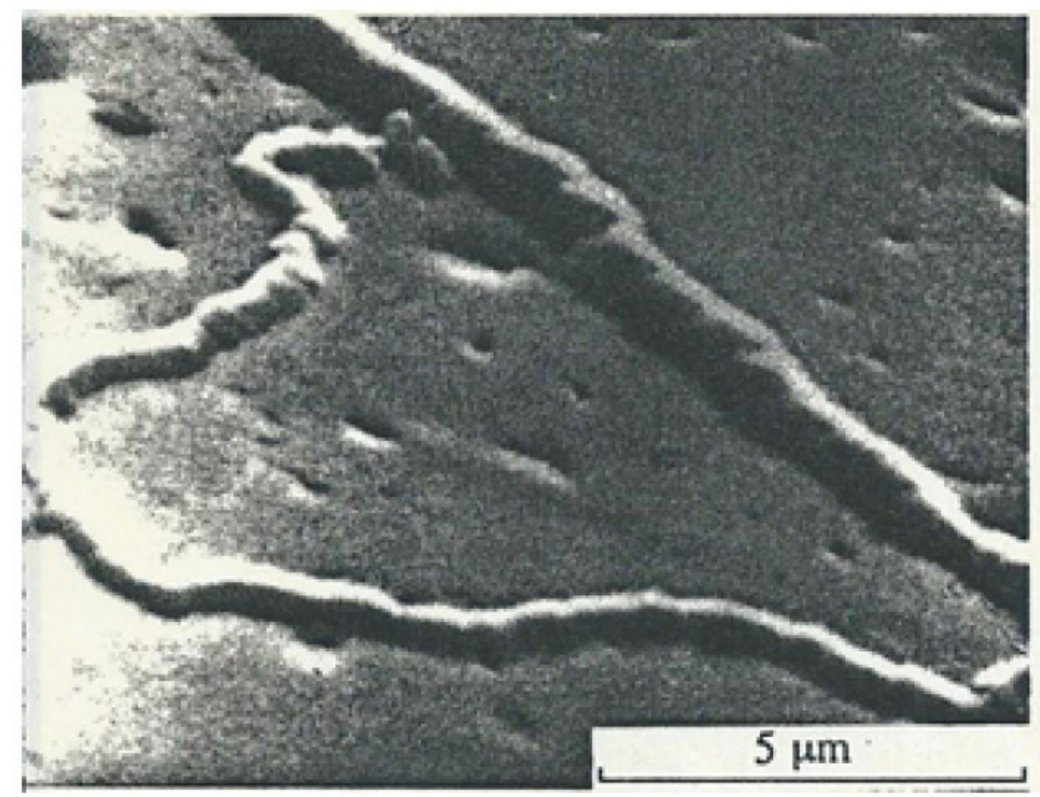

(a)

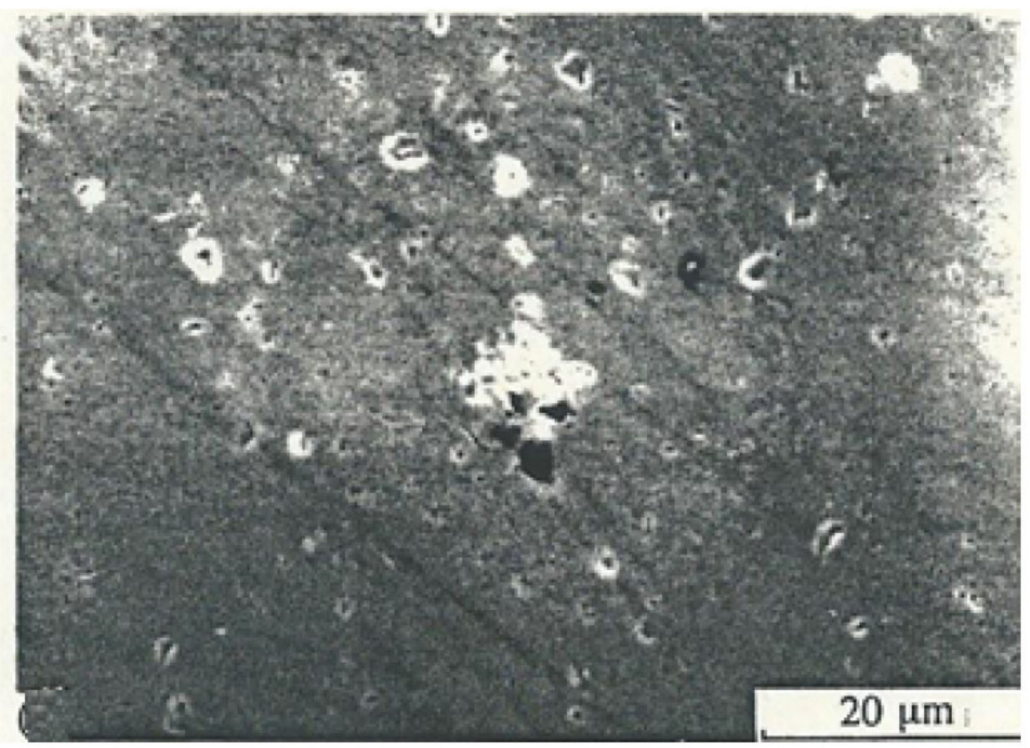

(b)

Figure 13. Scanning Electron Microscopy images of the iron surface after atmospheric corrosion test during $10 \mathrm{ks}$ at 100\% RH with 10 monolayers (a) and 18 monolayers (b) of BTMS [21]. Published with permission from NAUKA/INTERPERIODIKA 1994.

\section{Conclusions}

Thin butyl- and methyl-siloxane films were deposited on the iron surface from the mixed silane-water vapours in Ar flow. The piezo quartz microbalance was applied to determine the adsorption kinetics and the siloxane growth. It was pointed out that thin crystal-like films were adsorbed spontaneously depending on the pressure of water vapour in the mixture. An increase in humidity increased the thickness of the siloxane layer. The iron substrate catalysed the formation of $\mathrm{Fe}-\mathrm{O}-\mathrm{Si}$ and $\mathrm{Si}-\mathrm{O}-\mathrm{Si}$ bonds. This influence of the substrate is limited by the spontaneous adsorption of 6-12 monolayers of siloxane. Thin films show hydrophobic properties inhibiting water adsorption. 
Auger and X-ray Photoelectron spectroscopes were applied to investigate the surfaces. The formation of thin siloxane films was evidenced. Scanning Kelvin Probe was applied to study the iron-siloxane interface. Fe-O-Si bonds increased the potential of iron for $300-340 \mathrm{mV}$ due to the creation of the oriented layer of ionic dipoles at the interface. These bonds, in addition to iron oxide, passivate the iron surface.

Thin iron/siloxane joints were exposed in aggressive atmospheres containing high humid air and sulphur dioxide. Thin spontaneously adsorbed siloxane films show corrosion protection of the substrate due to the presence of $\mathrm{Fe}-\mathrm{O}-\mathrm{Si}$ bonds and high hydrophobicity. The corrosion stability is controlled by water adsorption that is influenced by the structure and thickness of the siloxane. The siloxane/iron surfaces are not stable after replacing air with an inert Ar. The oxygen of air passivates the surface oxide that preserves the iron-siloxane interfacial bonds and hydrophobicity of the substrate. Thus, oxygen shows inhibiting corrosion properties.

Author Contributions: Conceptualization, A.N., A.M., P.T.; writing of the article, M.P., A.M., A.N.; design of experiments, A.N., L.M., T.Y., P.T.; surface analytical investigations, P.T., A.N.; English editing, A.N. All authors have read and agreed to the published version of the manuscript.

Funding: This research was funded by the BASIC RESEARCH PROGRAM OF THE PRESIDIUM OF THE RUSSIAN ACADEMY OF SCIENCES, “Urgent Problems of Surface Physical Chemistry and Creation of New Composite Materials. Nanostructured Coatings for Electronics, Photonics, Alternative Energy Sources, and Materials Protection".

Institutional Review Board Statement: Not applicable.

Informed Consent Statement: Not applicable.

Data Availability Statement: Data is contained within the article.

Conflicts of Interest: The authors declare no conflict of interest.

\section{References}

1. Leidheiser, H.; Granata, R.D. Ion transport through protective polymeric coatings exposed to an aqueous phase. IBM J. Res. Dev. 1988, 32, 582-590. [CrossRef]

2. Thomas, N.L. The barrier properties of paint coatings. Prog. Org. Coat. 1991, 19, 101-121. [CrossRef]

3. Kinsella, E.M.; Mayne, J.E.O. Ionic conduction in polymer films I. influence of electrolyte on resistance. Br. Polym. J. 1969, 1, 173-176. [CrossRef]

4. Mayne, J.E.O.; Scantlebury, J.D. Ionic conduction in polymer films II. inhomogeneous structure of varnish films. Br. Polym. J. 1970, 2, 240-243. [CrossRef]

5. Kendig, M.; Mills, D.J. A historical perspective on the corrosion protection by paints. Prog. Org. Coat. 2017, 102, 53-59. [CrossRef]

6. Mills, D.J.; Jamali, S.S. The best tests for anti-corrosive paints. And why: A personal viewpoint. Prog. Org. Coat. 2017, 102, 8-17. [CrossRef]

7. Fowkes, F.M. Role of acid-base interfacial bonding in adhesion. J. Adhes. Sci. Technol. 1987, 1, 7-27. [CrossRef]

8. Negele, O.; Funke, W. Internal stress and wet adhesion of organic coatings. Prog. Org. Coat. 1996, 28, 285-289. [CrossRef]

9. Roche, A.A.; Bouchet, J.; Bentadjine, S. Formation of epoxy-diamine/metal interphases. Int. J. Adhes. Adhes. 2002, 22, 431-441. [CrossRef]

10. Aufray, M.; Roche, A.A. Is gold always chemically passive? Study and comparison of the epoxy-amine/metals interphases. Appl. Surf. Sci. 2008, 254, 1936-1941. [CrossRef]

11. Nazarov, A.; Thierry, D.; Volovitch, P.; Ogle, K. An SKP and EIS investigation of amine adsorption on zinc oxide surfaces. Surf. Interface Anal. 2010, 43, 1286-1298. [CrossRef]

12. Plueddemann, E.P. Silane Coupling Agents; Plenum: New York, NY, USA, 1982.

13. Wang, D.; Bierwagen, G.P. Sol-gel coatings on metals for corrosion protection. Prog. Org. Coat. 2009, 64, 327-338. [CrossRef]

14. Figueira, R.B.; Fontinha, I.R.; Silva, C.J.R.; Pereira, E.V. Review hybrid sol-gel coatings: Smart and green materials for corrosion mitigation. Coatings 2016, 6, 12. [CrossRef]

15. De Graeve, I.; Vereecken, J.; Franquet, A.; Van Schaftinghen, T.; Terryn, H. Silane coating of metal substrates: Complimentary use of electrochemical, optical and thermal analysis for the evaluation of film properties. Prog. Org. Coat. 2007, 59, 224-229. [CrossRef]

16. Criado, M.; Sobrados, I.; Sanz, J.; Bastidas, J.M. Steel protection using sol-gel coatings in simulated concrete pore solution contaminated with chloride. Surf. Coat. Technol. 2014, 258, 485-494. [CrossRef] 
17. Petrunin, M.A.; Nazarov, A.P.; Mikhailovskii, Y.N. Formation mechanism and anticorrosive properties of thin siloxane films on metal surfaces. J. Electrochem. Soc. 1996, 143, 251-257. [CrossRef]

18. Mohseni, M.; Mirabedini, M.; Hashemi, M.; Thompson, G.E. Adhesion performance of an epoxy clear coat on aluminum alloy in the presence of vinyl and amino-silane primers. Progr. Org. Coat. 2006, 57, 307-313. [CrossRef]

19. Mathiesen, E.; Nazarov, A.P.; Stratmann, M. In situ investigation of the adsorption of alkyltrimethoxysilanes on iron surfaces. Fresenius J. Anal. Chem. 1993, 346, 294-296. [CrossRef]

20. Nazarov, A.P.; Stratmann, M. Synthesis and properties of thin siloxane films on an iron surface. Russ. J. Phys. Chem. 1994, 68, 1007-1014.

21. Nazarov, A.P.; Stratmann, M. Adsorption of methoxysilanes on an iron surface and behaviour of formed surfaces in a corrosive environments. Prot. Met. 1994, 30, 52-58.

22. Nazarov, A.P.; Traverso, P.; Beccaria, A.M.; Thierry, D. Trimetoxysilane adsorption on iron surfaces; a scanning vibrating capacitor and electrochemical impedance study. Prot. Met. 1999, 35, 453-478.

23. Petrunin, M.A.; Nazarov, A.P.; Mikhaylovskii, Y.N. Adsorption and interphase interactions in metal—Silane and metal-silanepolymer systems. Prot. Met. 1993, 29, 225-231.

24. Sauerbrey, G. Verwendung von Schwingquarzen zur Wägung dünner Schichten und zur Mikrowägung. Z. Für Phys. 1959, 155, 206-222. [CrossRef]

25. Petrunin, M.A.; Gladkikh, N.A.; Maleeva, M.A.; Yurasova, T.A.; Terekhova, E.V.; Maksaeva, L.B. Application of the quartz crystal microbalance technique in corrosion studies: A review. Int. J. Corros. Scale Inhib. 2020, 9, 92-117.

26. Hölzl, J.; Schulte, F.K. Solid Surface Physics; Springer: Berlin/Heidelberg, Germany; New York, NY, USA, 1979 ; p. 2.

27. Samec, Z.; Johnson, B.W.; Capadonia, M.; Jauch, M.; Doblhofer, K. Kelvin probe measurements for chemical analysis: Interfacial structures. Sens. Actuators B 1993, 14, 741-744. [CrossRef]

28. Cappadonia, M.; Doblhofer, K. The electrical state of NAFION coated electrodes emersed from liquid electrolytes. Electrochim. Acta 1989, 34, 1815-1818. [CrossRef]

29. Yee, S.; Stratmann, M.; Oriani, R. Application of a Kelvin microprobe to the corrosion of metals in humid atmospheres. J. Electrochem. Soc. 1991, 138, 55-67. [CrossRef]

30. Nazarov, A.; Thierry, D. Application of Scanning Kelvin Probe in the study of protective paints. Front. Mater. 2019, 6, 192. [CrossRef]

31. Memming, R. Semiconductor Electrochemistry; Willey, VCH Verlag GmbH: Weinheim, Germany, 2000.

32. Taylor, D.M. Advances Developments in the theoretical modelling and experimental measurement of the surface potential of condensed monolayers. Colloid Interface Sci. 2000, 87, 183-203. [CrossRef]

33. Daves, J.T.; Rideal, E.K. Interfacial Phenomena; Academic: New York, NY, USA; London, UK, 1963.

34. Watts, J.F.; Wolstenholme, J. An Introduction to Surface Analysis by XPS and AES; Wiley \& Sons: Chichester, UK, 2003.

35. Davis, S.J.; Watts, J.F. Organization of methoxysilane molecules on iron. Int. J. Adhes. Adhes. 1996, 16, 5-15. [CrossRef]

36. Muniefa, W.-M.; Heibc, F.; Hempela, F.; Lua, X.; Schwartz, M.; Pachauria, V.; Hempelmannc, R.; Schmitt, M.; Ingebrandta, S. Silane deposition via gas-phase evaporation and high-resolution surface characterization of the ultra-thin siloxane coatings. Langmuir 2018, 34, 10217-10229. [CrossRef]

37. Boerio, F.J.; Dillingham, R.G. Adhesive Joints: Formation, Characterization and Testing; Mittal, K.L., Ed.; Plenum: New York, NY, USA, 1984; p. 541.

38. Nazarov, A.P.; Thierry, D. Scanning Kelvin probe study of metal/polymer interfaces. Electrochim. Acta 2004, 49, 2955-2964. [CrossRef]

39. Salgin, B.; Özkanat, Ö.; Mol, J.M.C.; Terryn, H.; Rohwerder, M. Role of surface oxide properties on the aluminum/epoxy interfacial bonding. J. Phys. Chem. C. 2013, 117, 4480-4487. [CrossRef]

40. Wielant, J.; Posner, R.; Hausbrand, R.; Grundmeier, G.; Terryn, H. SKP as a tool to study the physicochemical interaction at buried metal coating interfaces. Surf. Interface Anal. 2010, 42, 1005-10009. [CrossRef]

41. Nazarov, A.P.; Traverso, P.; Beccaria, A.M.; Thierry, D. Surface and Corrosion Chemistry of Iron with Grafted Silane Coupling Agents. In Proceedings of the EUROCORR'99, Aachen, Germany, 30 August-2 September 1999.

42. Nazarov, A.; Romano, A.-P.; Fedel, M.; Deflorian, F.; Thierry, D.; Olivier, M.-G. Filiform corrosion of electrocoated aluminium alloy: Role of the pre-treatment. Corros. Sci. 2012, 65, 187-198. [CrossRef] 